\title{
Art and archaeology: the visualisation of Orkney
}

Julia Sorrell*

Art and archaeology have always been an important part of my life, and it is only in the last couple of years that I have realised how I can unite them. Let me explain. I am the daughter of Alan Sorrell — an artist best known for his archaeological reconstruction drawings (Perry \& Johnson 2014: 323; Figure 1)_and throughout my childhood we visited sites around the country, linking work and holidays. As an artist, my father would gradually gather information to visualise yet another archaeological site while my brothers and I played. In time, I too became an artist fascinated by the abstraction and geometry of the natural world. When awarded the first TravelArt award 2015 by the ACE Foundation, I was asked to produce an exhibition of paintings of Orkney. This unleashed a latent desire to find my own personal interpretation of archaeology.

Over the centuries, there has been a union between art and archaeology. The art historian Sir Ernest Gombrich wrote that a pictorial representation

is not a faithful construction of a relational model. Neither the subjectivity of vision nor the sway of conventions need lead us to deny that such a model can be constructed to any required degree of accuracy. What is decisive here is clearly the word 'required.' The form of a representation cannot be divorced from its purpose and the requirements of the society in which the given visual language gains currency (1960: 90).

In the late 1930s, a re-discovery of the artist Thomas Guest (1754-1818) coincided with a wave of new artists, including Paul Nash, John Piper, Graham Sutherland, Henry Moore, Eric Ravilious and Alan Sorrell, who were inspired by the growing popular enthusiasm for archaeology. To varying degrees, they represented part of a modern British movement that often steered towards abstraction, surrealism and romanticism, while visualising our heritage and landscape (Hauser 2007: 22). Today, Guest is better remembered as the 'recorder' of beakers found during the excavation of barrows at Winterslow, Wiltshire (working alongside the Reverend A.B. Hutchins), than for the artistic quality of his paintings (Piggott 1978: 48). Paul Nash expressed a contrary relationship:

Avebury may rise again under the tireless hand of $M r$ Keiller, but it will be an archaeological monument, as dead as a mammoth skeleton in the Natural History Museum. When I stumbled over the sarsens in the shaggy autumn grass and saw the unexpected megaliths reared up among the corn stooks, Avebury was still alive (Smiles 2005: 11).

The archaeologist Alexander Keiller wanted clarity, whereas Nash wanted mystery. Henry Moore commented:

* Manor Farm, Wash Lane, Snetterton, Norwich NR16 2TU, UK (Email: julia@juliasorrell.com) 


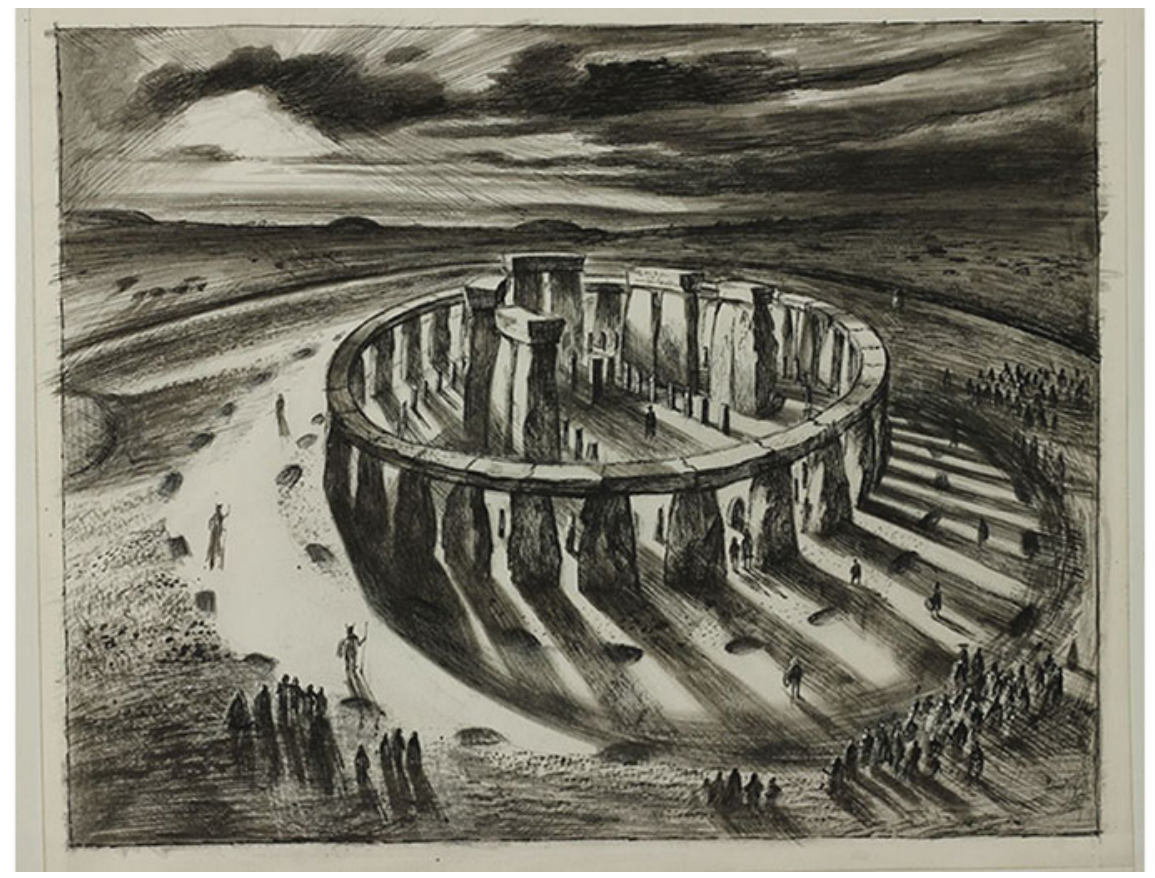

Figure 1. Stonehenge by Alan Sorrell (c. 1960) pen and ink, $18 \times 22 \mathrm{~cm}$.

I've read somewhere that certain primitive people coming across a large block of stone in their wanderings would worship it as a god-which is easy to understand, for there's a sense of immense power about a large rough-shaped lump of rock or stone (Denton 2002: 15).

Qualifying his approach to art, Nash wrote in April 1934: "I feel I am beginning now to find my way between 'Abstraction' and pure interpretation. As you know, I am far too interested in the character of landscape and natural forms generally" (Denton 2002: 18). Meanwhile, encouraged by V.E. Nash-Williams at the Museum of Wales, my father found a compromise, balancing information and clarity with mystery and romanticism, and consequently his work was in great demand from archaeologists (Perry \& Johnson 2014: 330).

With all this in mind, I arrived in Orkney to consider how to formulate an exhibition. Due to the inclement weather, I decided it was best to make careful drawings in my sketchbook, which would provide the necessary information once back in my Norfolk studio. I never work from photographs because they do not provide me with the relevant information to relate form as solid structures within space. Nevertheless, I was only too aware of the continual clicks of the cameras around me. So what, as an artist, could I contribute? As I walked around the Ring of Brogdar (Figure 2) and the Stones of Stenness (Figure 3), I was conscious of the majestic stones towering over the pilgrimage of tourists weaving in and out of them. These emotions I would not forget when recreating those magnificent Orcadian stones: how they had imperiously withstood the changing weather thrown at them for thousands of years, although sadly some had succumbed to the ravages of time. It (C) Antiquity Publications Ltd, 2017 


\section{Art and archaeology}

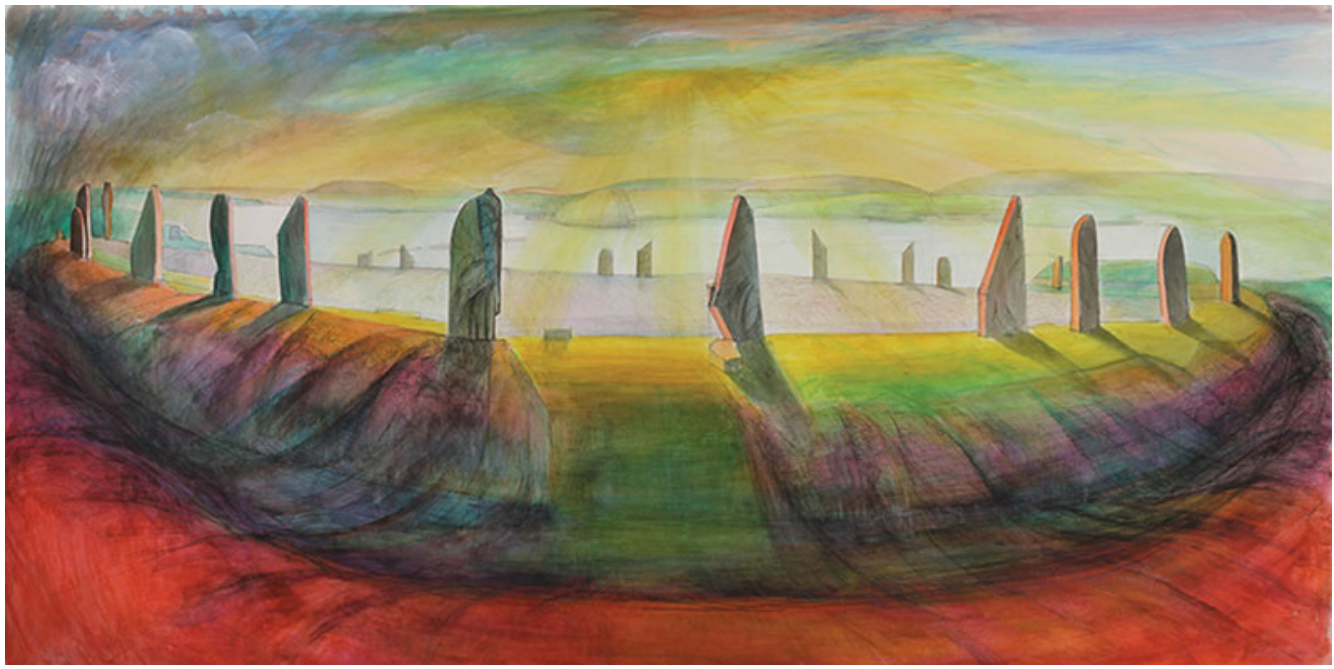

Figure 2. The Ring of Brodgar, Panorama (2016) pen and ink, watercolour, $67 \times 137 \mathrm{~cm}$.

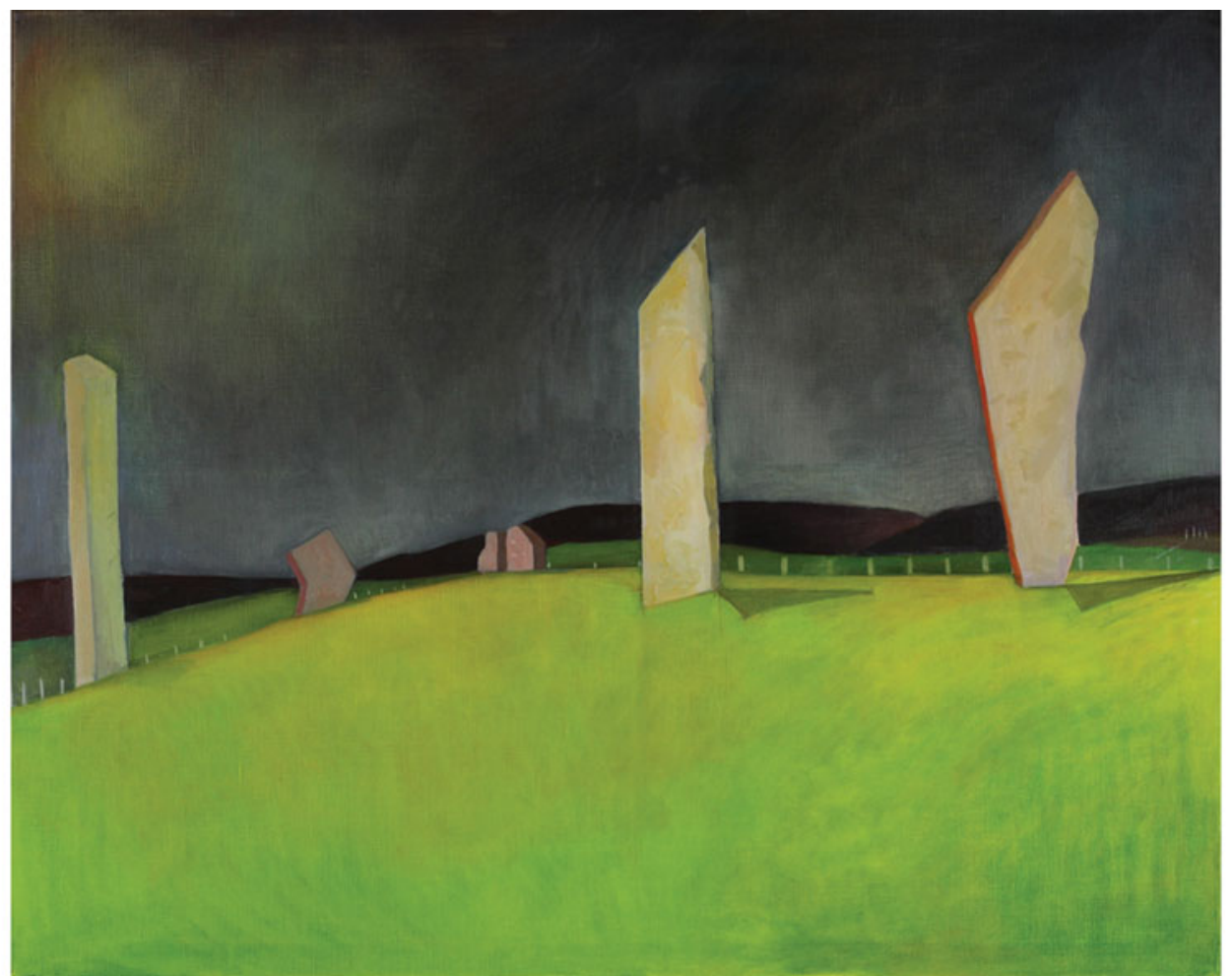

Figure 3. The Stones of Stenness after a Storm (2015) oil on canvas, $80 \times 100 \mathrm{~cm}$.

(C) Antiquity Publications Ltd, 2017 


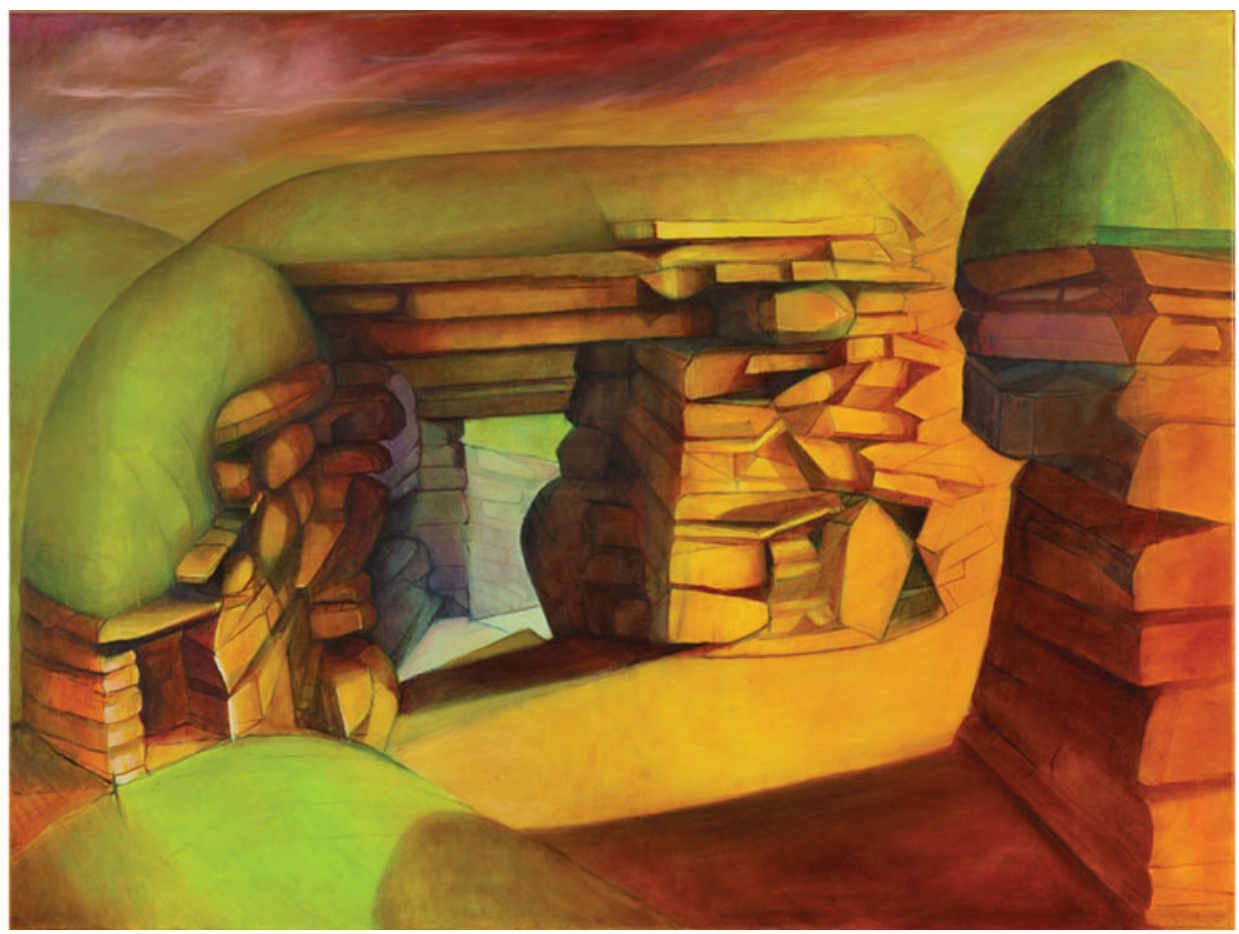

Figure 4. Homes and Passageways, Skara Brae (2016), oil on canvas, $76 \times 102 \mathrm{~cm}$.

was necessary to express all of this dramatic theatre against a backdrop of changing light with strong, direct drawing and emotive colours. Awkwardly clambering into cairns or peering enviously into the communal living places such as Skara Brae (Figure 4), I could almost hear the stories of their inhabitants as they huddled around the hearth while the winds roared outside. For five weeks I lived in a basic van, minus all modern comforts apart from a bed, in order to generate greater empathy with Orkney itself.

I tried to re-capture and articulate these sentiments in my paintings, visualising archaeology as part of the landscape, such as at Dwarfie Stane with the curving of the tomb reflected in the curve of the distant hill (Figure 5), or unavoidably linked to the coastline, where so often it is in danger of being eroded by the sea, wind and rabbits. At Midhowe Broch, I accentuated its potential fate of returning to the ravages of the sea by abandoning the modern defences (Figure 6). Time was also a factor, usually due to cold, rain or, in the case of Maeshowe (Figure 7), an allocated four hours with a Historic Scotland attendant sitting with me, as I carefully analysed the structure and geometry of this splendid cairn in eerie silence. I am honoured that the final painting is now part of the Cambridge McDonald Institute for Archaeological Research collection. In all of these paintings, a combination of line and washes of watercolour helped to explain form and three-dimensionality.

Many people are not necessarily informed about and, in fact, are intimidated by archaeology and history, so I considered it vital to reach as wide an audience as possible (C) Antiquity Publications Ltd, 2017 


\section{Art and archaeology}

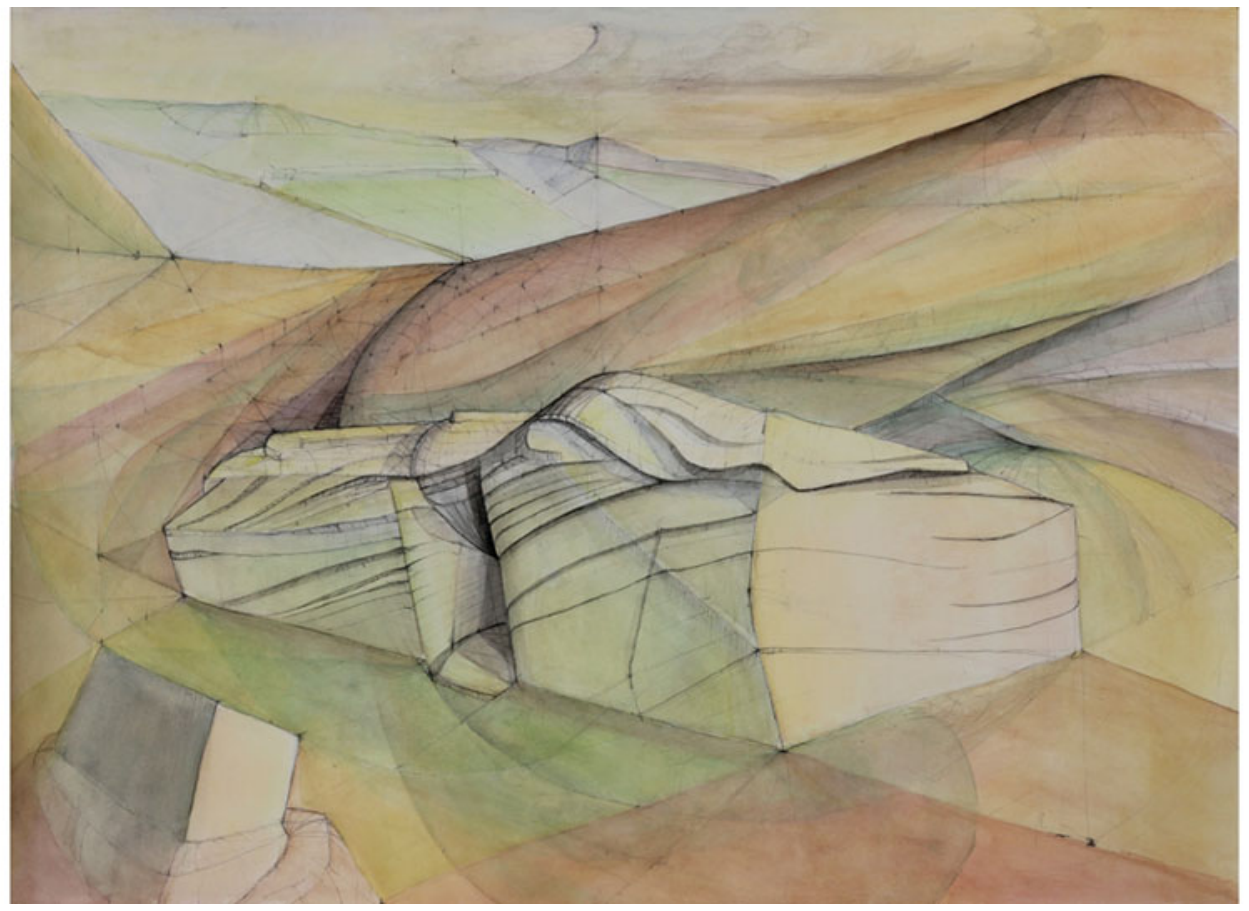

Figure 5. The Dwarfie Stane, Hoy (2015) pen and ink, watercolour, $53 \times 73 \mathrm{~cm}$.

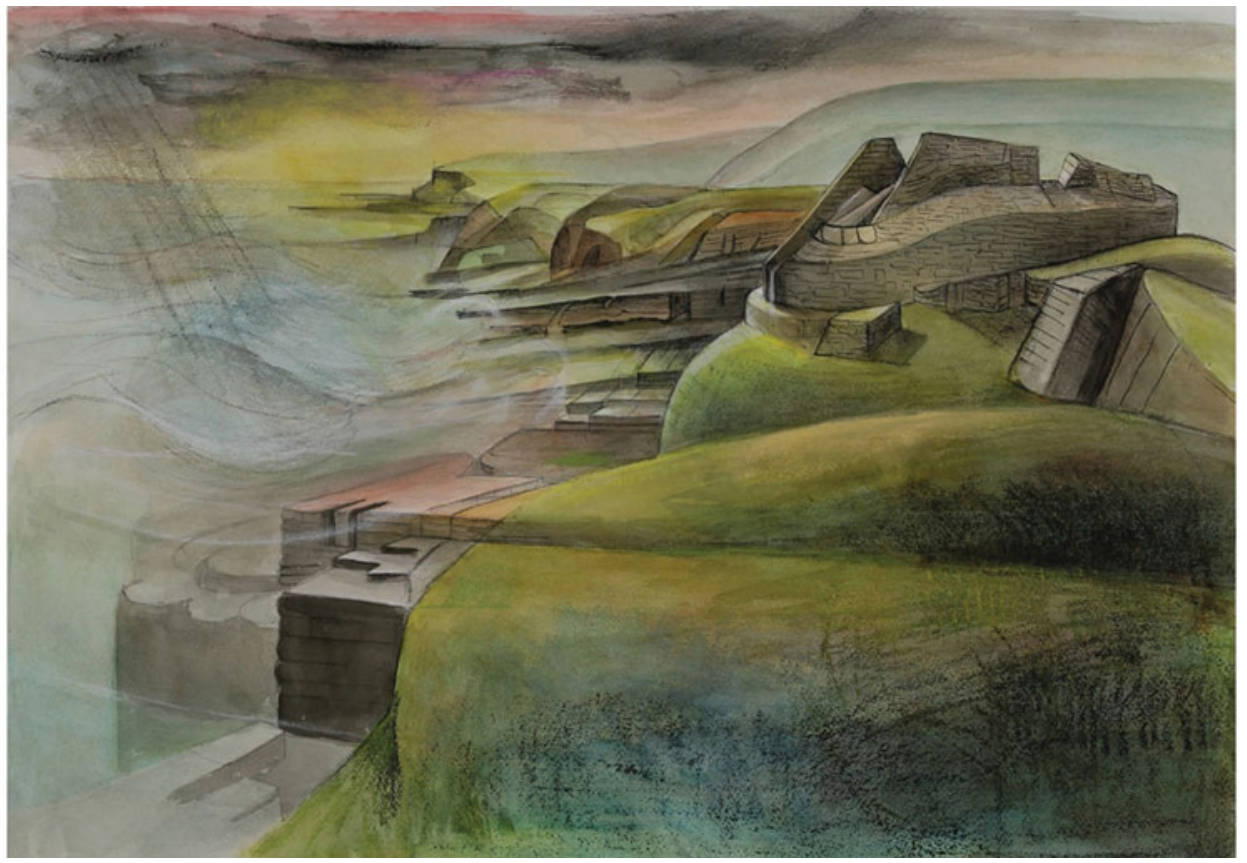

Figure 6. Coastline at Midhowe Broch, Rousay (2015) pen and ink, watercolour, $45 \times 65 \mathrm{~cm}$.

(C) Antiquity Publications Ltd, 2017 


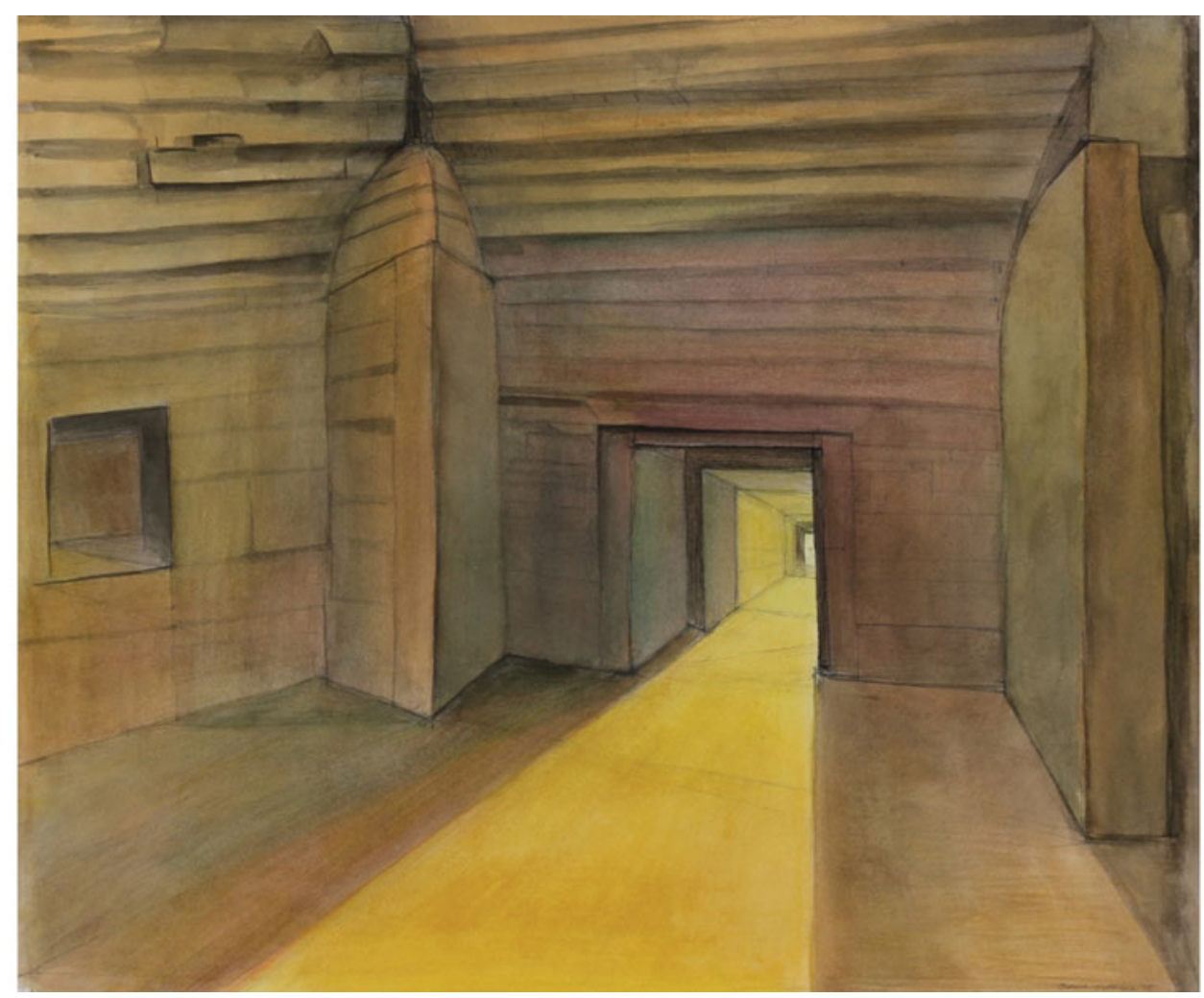

Figure 7. Maeshowe Chambered Cairn (2015) pen and ink, watercolour, $42 \times 52 \mathrm{~cm}$.

to make the greatest impact and widest connections. Linking art to archaeology, nature or science transcends all boundaries and is what an artist can do.

Finally, I created a $2.25 \mathrm{~m}$-tall sculpture entitled Reverence that was worked in handembroidery, and inspired by the Ring of Brogdar (Figures $8 \& 9$ ). Why hand-embroidery? I was able to draw the flowing lines with a needle rather than a pencil to create texture and form within a $3 \mathrm{D}$ structure. The tactile quality that hand-embroidery creates reminded me of the instinctive response to the standing stones of Orkney. The title Reverence symbolises a respect for our ancestors who had struggled to erect these massive monuments by hand to honour their gods.

I created Reverence with hand-embroidery-using hand-spun wool from British rarebreed sheep-an often over-looked art, dismissed so often as a woman's craft, and yet it originated from the sewing together of skins worn by our ancestors. I am delighted how people have connected emotionally to Reverence, as I had myself witnessed when drawing at the Ring of Brogdar, where people caressed and hugged the stones as if they were individual characters. Is this due to an innate human instinct to something hewn or sewn by hand, I wonder?

As a result of my long journey, supported by the ACE Foundation, I have attempted to connect to a wide cross-section of people, from craftsmen to archaeologists, and from

(C) Antiquity Publications Ltd, 2017 


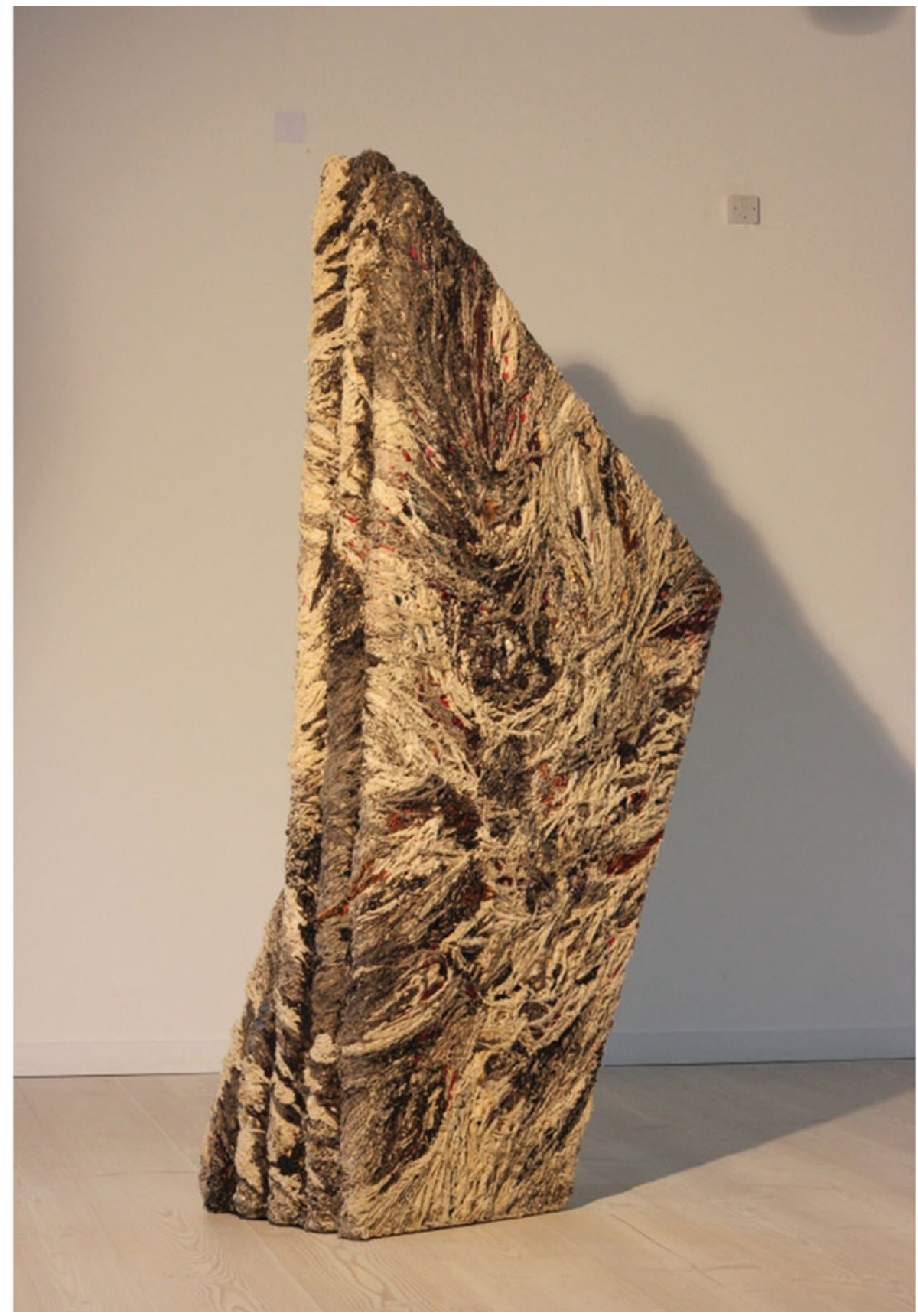

Figure 8. Reverence (2016), hand-embroidered hand-spun wool and silk on a wooden armature covered with chicken wire, $225 \mathrm{~cm}$ high.

(C) Antiquity Publications Ltd, 2017 


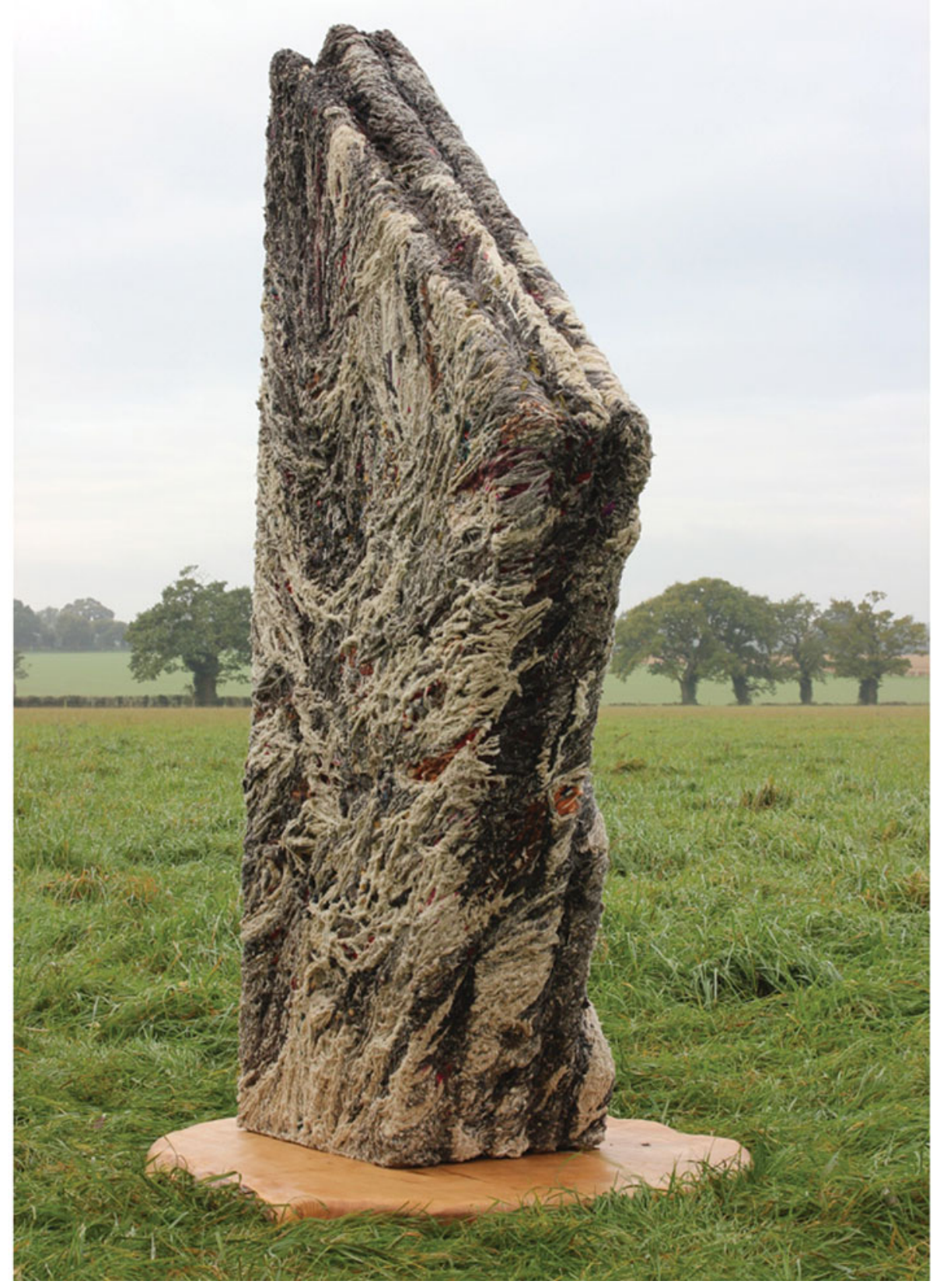

Figure 9. Reverence in a landscape.

(C) Antiquity Publications Ltd, 2017 
academics to non-academics, under the umbrella of Orkney through art. What next? I do not know, although some have suggested that Reverence and my paintings go on tour. I do, however, wish to explore further the visual world of archaeology and to continue the reinterpretation of our splendid and exciting heritage through the art of today. www.juliasorrell.com www.staplefordgranary.org.uk (Home of the ACE Foundation)

\section{References}

Denton, P. 2002. Seaside surrealism: Paul Nash in Swanage. Swanage: Peveril.

Gombrich, E.H. 1960. Art and illusion. New York: Phaidon.

Hauser, K. 2007. Shadow sites: photography, archaeology and the British landscape. Oxford: Oxford University Press.
Perry, S. \& M. Johnson. 2014. Reconstruction art and disciplinary practice: Alan Sorrell and the negotiation of the archaeological record. The Antiquaries Journal 94: 323-52. https://doi.org/10.1017/S0003581514000249

Piggott, S. 1978. Antiquity depicted, aspects of archaeological illustration. London: Thames \& Hudson. https://doi.org/10.1017/S0003581514000249

Smiles, S. 2005. Thomas Guest and Paul Nash in Wiltshire: two episodes in the artistic approach to British antiquity (Tate Papers 3). London: Tate. 